\title{
The Efficacy and Safety of Golimumab as Third- or Fourth-Line Anti-TNF Therapy in Patients with Refractory Crohn's Disease: A Case Series
}

\author{
Linda Russi Michael Scharl Gerhard Rogler Luc Biedermann \\ Department of Gastroenterology and Hepatology, University Hospital Zurich, and University of Zurich, \\ Zurich, Switzerland
}

\section{Keywords}

Anti-TNF agent-exposed patients · Crohn's disease · Difficult-to-treat Crohn's disease · Golimumab · TNF-a antagonist

\begin{abstract}
Background: The TNF-a antagonist golimumab is approved for the treatment of ulcerative colitis but not for Crohn's disease (CD). We herein report a case series of 8 difficult-to-treat patients with severe and refractory $C D$ receiving golimumab as an off-label rescue medication and fourth-line anti-TNF agent in our tertiary referral inflammatory bowel disease center. Methods: We performed a retrospective analysis of clinical, biochemical, and radiological as well as endoscopic parameters. The patients all suffered from severe refractory $\mathrm{CD}$ with ongoing symptoms. Moreover, all 8 patients had previously been treated with all 3 other TNF-a antagonists approved for CD in Switzerland (infliximab, adalimumab, and certolizumab pegol) without durable clinical response. Results: Three out of 8 patients showed a primary nonresponse. Among the 5 patients responding after induction, 1 patient showed a loss of response, and in 1 patient, treatment was terminated due to side effects. Three patients have a continuous clinical response under golimumab. We did not observe any severe adverse events during golimumab ad-
\end{abstract}

\section{KARGER}

(C) 2017 S. Karger AG, Basel

E-Mail karger@karger.com

www.karger.com/iid ministration. Conclusions: A considerable fraction of this highly selected subgroup of difficult-to-treat CD patients responded to golimumab, indicating a promising potential for refractory $C D$ patients, including those with multiple previous anti-TNF exposures.

(c) 2017 S. Karger AG, Basel

\section{Introduction}

Golimumab (Simponi ${ }^{\circledR}$, Janssen, Beerse, Belgium) is a fully human IgG1 monoclonal antibody, which inhibits tumor necrosis factor alpha (TNF-a) [1]. It is 1 of 4 TNF- $\alpha$ antagonists available for treating inflammatory bowel disease (IBD). The other agents approved for IBD in Switzerland are adalimumab, infliximab, and certolizumab pegol. Golimumab is approved for the subcutaneous (s.c.) and intravenous treatment of rheumatoid arthritis [2-6] and s.c. treatment of ankylosing spondylitis [7], psoriatic arthritis [8], and ulcerative colitis [6, 9, 10]. However, despite the well-established efficacy of the other 3 anti-TNF agents available for Crohn's disease (CD), golimumab has not been explored for this indication. This may be due to a multitude of reasons, including strategical considerations by the manufacturer and regulatory issues/burden.
Luc Biedermann

Department of Gastroenterology and Hepatology University Hospital Zurich

Rämistrasse 100, CH-8091 Zurich (Switzerland)

E-Mail luc.biedermann@usz.ch 
There are neither clinical trials nor case series on golimumab in $\mathrm{CD}$ available in the literature, except for a small retrospective series in 6 children from Finland, reporting modest beneficial effects [11]. Despite substantial progress with a growing number of therapeutic agents in recent years and an impressively large pipeline of emerging treatment options $[12,13]$, many unmet needs and treatment gaps remain in CD [14].

Eight patients with severe CD from the IBD clinic at the University Hospital of Zurich received off-label golimumab after all other approved TNF- $\alpha$ antagonists, immunosuppressants, and experimental therapies within clinical trials had either turned out inefficient or had caused intolerable adverse effects. All patients were previous anti-TNF responders to at least 1 agent. Primary antiTNF nonresponders were not considered for off-label golimumab treatment. We herein report on our therapeutic experience with golimumab in $\mathrm{CD}$ in this case series, which is, to the best of our knowledge, the first published experience in adult CD patients.

\section{Materials and Methods}

We retrospectively analyzed our patient database from the IBD clinic at the University Hospital of Zurich including all CD patients ever having received at least 1 dose of golimumab. We reviewed patients' medical history regarding demographics, disease characteristics, course of the disease, treatment history as well as current medication, and clinical data regarding efficacy of golimumab (including adverse events, endoscopy, and imaging results whenever available). Our center features an electronic database with a standardized report form, including, amongst others, Harvey Bradshaw index, current and previous medication, extraintestinal manifestations (EIMs), comorbidities, and adverse events.

\section{Ethical Considerations}

The off-label use of golimumab in our CD patients was individually approved by the patients' health insurances. Due to recent changes in the Swiss Law on Human Research (Humanforschungsgesetz), the patients signed a general consent to use their data for scientific purposes at the beginning of 2016, allowing retrospective data analysis.

\section{Results}

All 8 patients suffered from refractory CD and had previously received 3 anti-TNF agents as well as several other approved and investigational drugs. In addition, all patients suffered from an extensive bowel involvement and the majority also from EIMs, especially on the joints and skin. Likewise, a stricturing and penetrating disease behavior occurred in most cases. The patients showed a variable response to previous treatments, with either primary nonresponse or loss of response as well as side effects requiring drug cessation. Several patients had previously undergone surgery (some repetitively), including ileocecal resection and perianal fistulae surgery, abscesses drainage, and even colectomy. In the following, a brief description of each individual case is provided.

\section{Case 1}

A 44-year-old man, who was a former smoker with a long history of spondyloarthropathy, had been suffering from steroid-refractory CD for 18 years (Montreal classification: A1, L3, B3; Table 1). CD was localized in the terminal ileum, colon, and rectum. He also suffered from recurrent perianal fistulae requiring surgery. The list of previous treatments included 5ASA (mesalamine), steroids, infliximab (which was initially successful but later induced an allergic reaction), and subsequently adalimumab, which was ineffective. He did not tolerate azathioprine (arthralgia, nausea). Subsequently, certolizumab combined with methotrexate was administered. After diagnosis of liver fibrosis, methotrexate was stopped. Shortly after withdrawal of methotrexate, a loss of response to certolizumab pegol therapy occurred. Golimumab combined with 6-mercaptopurine was started. After initial clinical improvement, the interval of golimumab injection had to be shortened due to an increase in clinical symptoms. In addition, the patient repeatedly suffered from a Clostridium difficile infection, further impairing his clinical condition. However, overall, the patient's condition during treatment with golimumab considerably improved (notable clinical response but not remission), oral steroids could be tapered (from $10 \mathrm{mg}$ to $2.5 \mathrm{mg}$ prednisone per day), and biochemical improvement was observed in parallel (Table 2). The patient is currently still under golimumab treatment with mild disease symptoms.

\section{Case 2}

A 46-year-old nonsmoking man with a 24-year history of steroid-dependent CD without EIMs suffered mainly from involvement of the ileum (Montreal classification: A1, L3, B3). During the disease course, he developed 2 ileal strictures requiring surgery. Two blind-ending fistulae originating from the terminal ileum were seen on magnetic resonance imaging (MRI). He had been treated with mesalazine and azathioprine, without success, and with certolizumab, with initial treatment response but a rapid loss of response. Next, infliximab treatment was 


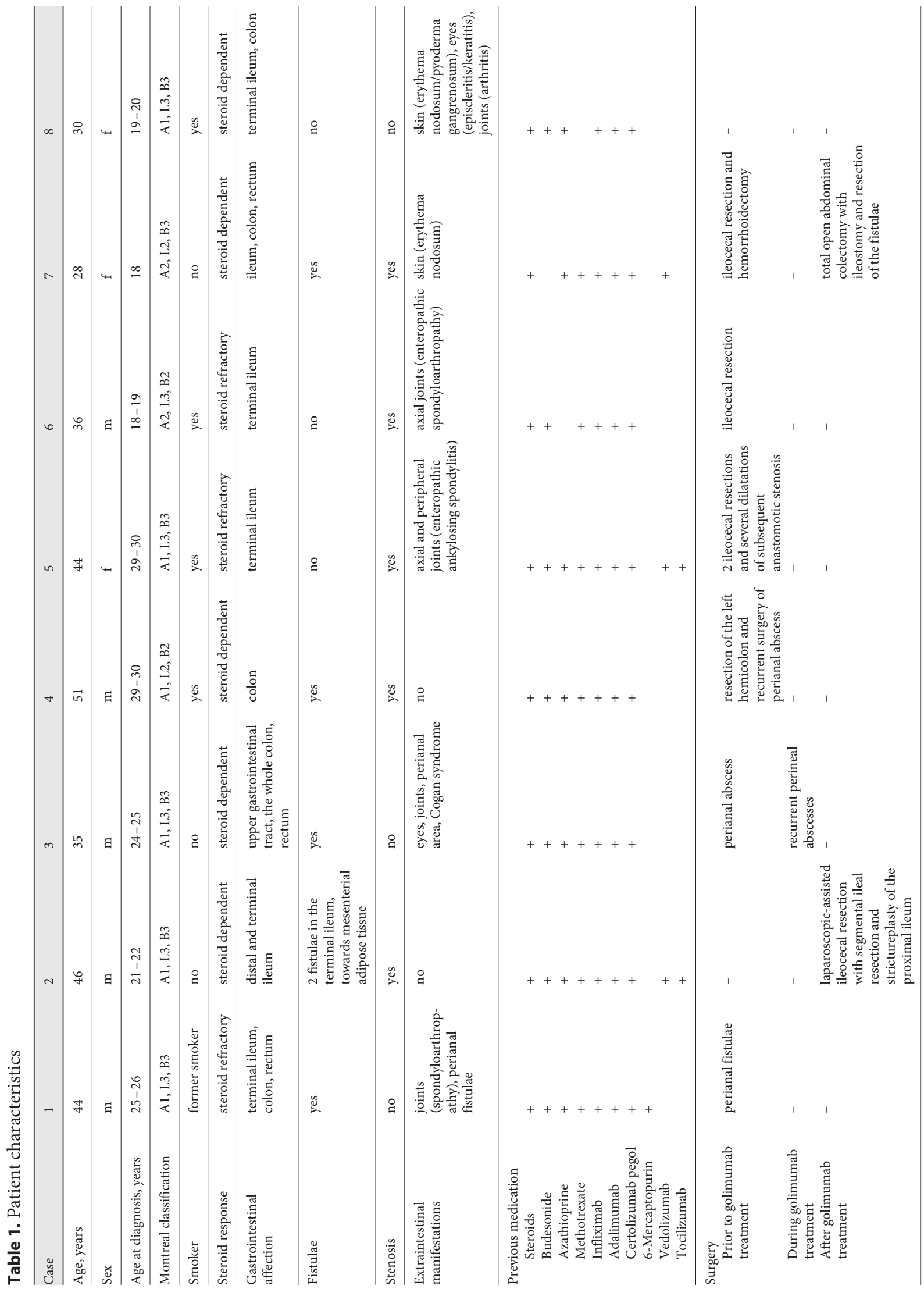


Table 2. Endoscopy, imaging, and laboratory findings (when available)

\begin{tabular}{|c|c|c|c|}
\hline Case & Prior to golimumab treatment & During golimumab treatment & After golimumab treatment \\
\hline $\begin{array}{ll}\text { a } & \mathrm{Er} \\
1 & \end{array}$ & $\begin{array}{l}\text { doscopy, imaging } \\
\text { Colo: left-sided colitis }\end{array}$ & & \\
\hline 2 & $\begin{array}{l}\text { MRI: progressive affection of the distal and } \\
\text { terminal ileum with a light prestenotic dilatation, } \\
\text { enlarged mesenterial lymph nodes; Colo: distinct } \\
\text { ileitis, stenosis (probably due to inflammatory } \\
\text { edema), solitary aphthous ulcerations in the } \\
\text { descending colon }\end{array}$ & $\begin{array}{l}\text { MRI: constant result, except no prestenotic } \\
\text { dilatation and } 2 \text { fistulae from the terminal } \\
\text { ileum to the mesenterial adipose tissue }\end{array}$ & \\
\hline 3 & $\begin{array}{l}\text { Rectosigmoidoscopy: active colitis and proctitis; } \\
\text { Sono: active colitis }\end{array}$ & $\begin{array}{l}\text { Sono: suspected active colitis especially in } \\
\text { the colon transversum; Colo: CD without } \\
\text { active inflammation }\end{array}$ & \\
\hline 4 & $\begin{array}{l}\text { MRI: focal colitis in the descending colon with } \\
\text { perifocal abscess formation, complex perianal } \\
\text { system of fistulae; CT: new fistulae }\end{array}$ & $\begin{array}{l}\text { Colo: persisting pancolitis, perianal } \\
\text { nonirritated fistula }\end{array}$ & \\
\hline 5 & $\begin{array}{l}\text { Colo: stenosis of the anastomosis, light ileitis, } \\
\text { edematous colon; MRI: inflammatory reaction in } \\
\text { the neoterminal ileum, progressive reactive } \\
\text { lymphadenopathy }\end{array}$ & $\begin{array}{l}\text { MRI and Colo: constant result; capsule } \\
\text { endoscopy: multiple ulcerations in the distal } \\
\text { ileum; rectosigmoidoscopy: distal proctitis, } \\
\text { light ulcerations }\end{array}$ & $\begin{array}{l}\text { MRI: constant result; Colo: constant result, } \\
\text { except slightly ulcerative pancolitis }\end{array}$ \\
\hline 6 & $\begin{array}{l}\text { Colo: inflammatory altered ileocecal valve; MRI: } \\
\text { long fibrostenosis in the ileum; Sono: long severe } \\
\text { ileitis; Sono: after the operation slightly prominent } \\
\text { ileum }\end{array}$ & $\begin{array}{l}\text { Sono: constant result; Sono: light wall } \\
\text { thickening in the neoterminal ileum }\end{array}$ & \\
\hline 7 & $\begin{array}{l}\text { Colo: severe pancolitis with ulcerations and } \\
\text { pseudopolyps, increased friability; Colo: after the } \\
\text { ileocecal resection, severe colitis, possible fistula, } \\
\text { light stenosis; MRI: disappeared haustration, short } \\
\text { fistula between the distal jejunum/proximal ileum } \\
\text { and the descending colon }\end{array}$ & $\begin{array}{l}\text { Colo: severe inflammatory activity in the } \\
\text { colon and the neoterminal ileum, stenosis } \\
\text { and fistula }\end{array}$ & $\begin{array}{l}\text { MRI: fistula from the sigmoid colon through } \\
\text { the musculus rectus to the subcutaneous } \\
\text { adipose tissue; Colo: fistula from the distal } \\
\text { sigmoid colon to the bladder, enterosigmoid } \\
\text { fistula, highly active colitis }\end{array}$ \\
\hline 8 & $\begin{array}{l}\text { MRI: wall thickening of the terminal ileum and the } \\
\text { colon, abdominal lymphadenopathy }\end{array}$ & & $\begin{array}{l}\text { Sono: distinct colitis transversum and } \\
\text { ascendens, wall thickening in the terminal } \\
\text { ileum; Colo: inflammatory alterations in the } \\
\text { terminal ileum, the colon ascendens and } \\
\text { transversum, stenotic and inflammatory } \\
\text { altered valve }\end{array}$ \\
\hline
\end{tabular}

\begin{tabular}{|c|c|c|c|}
\hline 1 & $\begin{array}{l}\text { CRP: } 13 \text {, Lc: } 12.75 \text {, Thromb: } 345, \mathrm{Hb}: 113 \text {, } \\
\text { calprotectin: } 1330\end{array}$ & $\begin{array}{l}\text { CRP: } 8.1 \text {, Lc: } 5.28 \text {, Thromb: } 129, \text { Hb: } 147 \text {, } \\
\text { calprotectin: } 1,037\end{array}$ & \\
\hline 2 & $\begin{array}{l}\text { CRP: } 19 \text {, Lc: } 5.83 \text {, Thromb: } 370, \text { Hb: } 131 \text {, } \\
\text { calprotectin: } 1,855\end{array}$ & $\begin{array}{l}\text { CRP: } 3.5 \text {, Lc: } 17.35 \text {, Thromb: } 346, \mathrm{Hb}: 90 \text {, } \\
\text { calprotectin: } 189\end{array}$ & $\begin{array}{l}\text { CRP: }<0.3 \text {, Lc: } 6.67, \text { Thromb: } 227, \text { Hb: } 146 \text {, } \\
\text { calprotectin: }<30\end{array}$ \\
\hline 3 & $\begin{array}{l}\text { CRP: } 11 \text {, Lc: } 12.71 \text {, Thromb: } 424, \text { Hb: } 154 \text {, } \\
\text { calprotectin: } 932\end{array}$ & $\begin{array}{l}\text { CRP: } 1.1, \text { Lc: } 8.18 \text {, Thromb: } 376, \mathrm{Hb}: 164 \text {, } \\
\text { calprotectin: } 405\end{array}$ & \\
\hline 4 & $\begin{array}{l}\text { CRP: } 5.6 \text {, Lc: } 8.45 \text {, Thromb: } 406 \text {, Hb: } 134 \text {, } \\
\text { calprotectin: } 242\end{array}$ & CRP: 1.4, Lc: 8.84, Thromb: 241, Hb: 159 & \\
\hline 5 & $\begin{array}{l}\text { CRP: } 2.4 \text {, Lc: } 10.88 \text {, Thromb: } 380, \text { Hb: } 130 \text {, } \\
\text { calprotectin: } 113\end{array}$ & $\begin{array}{l}\text { CRP: } 2.2 \text {, Lc: } 13.17 \text {, Thromb: } 360, \text { Hb: } 126 \text {, } \\
\text { calprotectin: } 171\end{array}$ & CRP: 4.1, Lc: 9.06, Thromb: 388, Hb: 107 \\
\hline 6 & $\begin{array}{l}\text { CRP: } 21, \text { Lc: } 7.65 \text {, Thromb: } 285 \text {, Hb: } 125 \text {, } \\
\text { calprotectin: } 1,387\end{array}$ & $\begin{array}{l}\text { CRP: } 2.6, \text { Lc: } 8.19 \text {, Thromb: } 229, \text { Hb: } 146 \text {, } \\
\text { calprotectin: } 290\end{array}$ & \\
\hline 7 & $\begin{array}{l}\text { CRP: } 22 \text {, Lc: } 6.51 \text {, Thromb: } 531 \text { Hb: } 80 \text {, } \\
\text { calprotectin: } 5,489\end{array}$ & & $\begin{array}{l}\text { CRP: } 31 \text { Lc: } 6.57 \text {, Thromb: } 498, \text { Hb: } 94 \text {, } \\
\text { calprotectin: } 428\end{array}$ \\
\hline 8 & Calprotectin: 1,343 & & CRP: 88, Lc: 11.09, Thromb: 379, Hb: 120 \\
\hline
\end{tabular}

Colo, colonoscopy; MRI, magnetic resonance imaging; Sono, sonography; CT, computed tomography; CD, Crohn's disease; CRP, C-reactive protein; Lc, leucocytes; Thromb, thrombocytes; Hb, hemoglobin. 
initiated, which was clinically effective but had to be stopped due to an infusion reaction. Subsequently, the patient received adalimumab associated with a primary nonresponse and then participated in a multi-center phase II trial with an anti-IL-6 antibody. Finally, the patient received golimumab for 7 months. Due to a potential fibrostenotic ileal involvement, the patient again showed a primary nonresponse, and the decision for laparoscopic-assisted ileocecal resection with a segmental ileal resection and a strictureplasty of the proximal ileum was made. During golimumab treatment, neither clinical symptoms nor laboratory and MRI findings did improve.

\section{Case 3}

A 35-year-old nonsmoking man had been suffering from a steroid-dependent CD (Montreal classification: A1, L3, B3) with several EIMs, including involvement of the eyes and the joints, for 10 years. He also had Cogan syndrome with deafness as a result of a bilateral cochleovestibular disorder $[15,16]$. The upper gastrointestinal tract and the entire colon and rectum were affected. Several perineal abscesses and a perianal fistula required surgical treatment. Initially, he was treated with azathioprine with primary nonresponse. Thereafter, he consecutively received infliximab, certolizumab, and adalimumab, all with a rapid loss of response or nonresponse as well as with an infliximab-induced hepatitis. Methotrexate was not tolerated due to nausea and impairment of taste. Treatment with cyclosporine had to be stopped due to neurotoxicity and insufficient response. Subsequently, golimumab was started with an initially limited response to the 50-mg dosing every 4 weeks. In this situation, the dose was increased to $100 \mathrm{mg}$, and the administration interval was shortened to 2 weeks. The patient initially showed a prolonged clinical response with clinical and laboratory improvement. However, steroids could not be permanently reduced below $20 \mathrm{mg}$ of prednisone per day, and no evident improvement on ultrasound and endoscopic findings could be observed. During ongoing treatment with golimumab of 4 years, the patient had to undergo surgical treatment of perineal abscesses twice. Due to lack of success in tapering systemic steroids, moderate residual endoscopic inflammatory activity, as well as clinical symptoms, we considered this case as loss of response to golimumab despite undoubtable overall temporary clinical benefit.

\section{Case 4}

A 51-year-old smoking man (45 pack-years) with a 21year history of steroid-dependent CD (Montreal classifi-

Golimumab in Refractory Crohn's

Disease cation: A1, L2, B2) developed several abscesses, fistulae, and stenosis. Initially, he was treated with steroids and then azathioprine, which caused a pancreatitis. Infliximab, adalimumab, and certolizumab were administered subsequently with primary response to all 3 agents, however, followed by loss of response to all TNF inhibitors. Thereafter, the patient participated in a phase II trial with a s.c. anti-integrin antibody with primary nonresponse and early treatment withdrawal after entering the early open-label phase. Due to severe active inflammatory involvement of the descending colon and sigma, a retroperitoneal abscess formation, and development of an enterocutaneous fistula, segment resection of the left hemicolon was performed. After surgery, golimumab was initiated as there was residual inflammation in the remaining left colon proximal and distal to the anastomosis. Seven months after the colonic resection, the ileostomy was reversed. Seven months after the initiation of golimumab, mild-to-moderate diarrhea reappeared at the end of the 4-week golimumab interval, and the fistula was clinically reactivated. Therefore, treatment with golimumab was continued in a combination with methotrexate (15 mg s.c. once per week) despite a lack of supporting data for methotrexate/golimumab combination treatment in $\mathrm{CD}$, with consecutive absence of clinical symptoms at the end of the 4-week interval. The patient currently is in clinical remission and is still under golimumab in combination with methotrexate for more than 1 year.

\section{Case 5}

A 44-year-old woman was diagnosed with CD 14 years ago and developed a steroid-refractory disease course (Montreal classification: A1, L3, B3). She was a smoker and had an affection of the terminal ileum, where she also had a stenosis. In addition, she suffered from enteropathic ankylosing spondylitis. The patient underwent ileocecal resection twice within 9 years and had repeated dilatations of the anastomosis. She had sequentially been treated with azathioprine, methotrexate, budesonide, vedolizumab, infliximab, adalimumab, certolizumab, tocilizumab (an already available antibody directed against IL-6, approved for rheumatoid arthritis), cyclosporine, and tacrolimus, all with primary nonresponse, except for infliximab (loss of response after initial good response). A re-exposure to infliximab had to be stopped due to a psoriasiform exanthema, insufficient through level, and antibodies to infliximab. Thus, golimumab was started in combination with azathioprine. Steroids could be completely withdrawn. However, no biochemical or endo-

Inflamm Intest Dis 2017;2:131-138 DOI: $10.1159 / 000481400$ 
scopic improvement was observed. In view of the residual clinical symptoms, the patient was considered as a primary nonresponder, and golimumab was stopped.

\section{Case 6}

A 36-year-old smoking man had been suffering from steroid-refractory CD for 17 years (Montreal classification: A2, L3, B2) with enteropathic spondyloarthropathy. In the terminal ileum, he had a long fibrostenotic lesion. He had been treated with infliximab and adalimumab (intermittently in combination with methotrexate) with primary nonresponse. The patient had received certolizumab with a positive effect on his rheumatologic symptoms. An ileocecal resection was performed, certolizumab was stopped, and golimumab was started, resulting in clinical remission. The back pain and the laboratory findings consecutively improved.

\section{Case 7}

A 28-year-old nonsmoking woman had been suffering from steroid-dependent CD (Montreal classification: A2, L2, B3) for 10 years. She had disease activity in the ileum, colon, and rectum and developed several fistulae, stenosis, and an erythema nodosum. Besides, she repeatedly needed blood transfusions because of recurring anemia as a result of chronic inflammation, blood loss, and iron as well as vitamin $B_{12}$ deficiency. She had been treated with azathioprine and, thereafter, with infliximab, which was stopped because of worsening of symptoms. After ileocecal resection, the patient again received infliximab, which caused a severe allergic reaction with exanthema and bronchospasm. Subsequently, certolizumab and adalimumab were administered, both inducing clinical response, but a loss of response after 2 and 6 months, respectively, occurred. Ustekinumab was given with a 270 $\mathrm{mg}$ s.c. induction dose followed by $90 \mathrm{mg}$ every 8 weeks s.c. Due to an insufficient clinical response to ustekinumab, golimumab was started. There was no clinical benefit and no endoscopic improvement. A decision for total colectomy with ileostomy and resection of the fistulae was made, and significant clinical improvement after the surgical intervention occurred.

\section{Case 8}

A 30-year-old smoking woman had been suffering from steroid-dependent CD for 10 years (Montreal classification: A1, L3, B3). She had several EIMs (erythema nodosum/pyoderma gangrenosum, episcleritis/keratitis, and arthritis). The terminal ileum and the colon were affected. The medical treatment consisted initially of aza- thioprine. Afterwards, infliximab was given, which had to be withdrawn due to exanthema and loss of response. Certolizumab had to be stopped due to a severe psoriasiform skin reaction. Next, treatment with adalimumab had to be withdrawn due to a rapid loss of response. Golimumab was given, inducing clinical response. However, due to the appearance of oro-facio-genital pustules, golimumab was also stopped. The patient was subsequently included into clinical trials and has still active disease at present.

\section{Discussion}

In our case series, we report on the clinical potential of golimumab in adult CD patients, involving a highly selective population of tertiary referral centers' difficult-totreat, refractory, and treatment-exposed patients. The final outcome of our 8 patients was primary nonresponse in 3 cases, loss of response in 1 case, cessation due to side effects in 1 case, and ongoing clinical response in 3 patients. We did not observe severe adverse events associated with golimumab, with the exception of severe psoriasiform pustulosis. This side effect is a well-known complication of anti-TNF treatment.

Evidently, in each patient in this series, the odds of response prior to initiation were not in favor of golimumab, as all patients aggregated at least 1 but mostly several risk factors for primary nonresponse or loss of response, i.e., long disease duration; previous treatment failure to all other TNF-inhibiting agents available for CD in Switzerland as well as a multitude of established and investigational agents; preexisting severe and extensive intestinal alterations; previously experienced side effects to antiTNF and other agents; and active smoking.

Therefore, considering the overall baseline characteristics and the difficult-to-treat patient profile of our small cohort, the overall clinical results of golimumab are noteworthy. In most European countries, there are 3 TNF- $\alpha$ antagonists available and approved for ulcerative colitis but only 2 for $\mathrm{CD}$. With the new treatment options on the horizon, such as vedolizumab, ustekinumab, mongersen, and Janus kinase inhibitors, the availability of a third or fourth anti-TNF agent for refractory CD may be less of an issue in the future. However, for all of these compounds, considerable gaps in efficacy, such as steroid-free clinical remission or mucosal healing, have been reported. In addition, none of these agents have been tested against antiTNF agents. Thus, it remains unclear whether these emerging treatment options are superior to anti-TNF
136

Inflamm Intest Dis 2017;2:131-138 DOI: $10.1159 / 000481400$
Russi/Scharl/Rogler/Biedermann 
agents. Allez et al. [17], several years ago, showed that there is a place for a third anti-TNF agent, even after 2 prior anti-TNF antibodies had failed. Accordingly, and one step further, this small case series suggests that even a fourth anti-TNF-inhibiting agent may have some clinical potential in refractory $\mathrm{CD}$ patients with prior triple anti-TNF agent failure. In addition, golimumab has the advantage of a well-known safety profile $[9,10]$. For offlabel use in CD in Switzerland, a specific agreement with the health insurance company, the manufacturer, or a combination of both is necessary. Treatment costs are in a comparable range with other biologics in the field of IBD. Thus, we believe that golimumab apparently may represent a yet underused rescue treatment option in CD.

As with any case series, our report has several limitations, including the difficulty to compare patients with a nonstandardized follow-up, retrospective analysis, and single-center design. Furthermore, we report on an insufficient number of patients for robust calculation of response and remission values, and there is a lack of comparison to clinical trial data of other agents. However, if a bias would have to be expected in terms of efficacy, rather an underestimation of the clinical effect might have occurred in this highly selected fraction of refractory and highly treatment-exposed CD patients. Ideally, a prospective double-blind randomized clinical trial of golimumab in CD would provide robust data on its efficacy. However, in view of strategic considerations of the manufacturer, such a trial most likely will not be performed.
In conclusion, golimumab has a clinical potential and is safe in severe refractory and highly treatment-exposed CD patients, even after multiple prior anti-TNF agent exposures and failure of treatment.

\section{Statement of Ethics}

Due to recent changes in the Swiss Law on Human Research (Humanforschungsgesetz), the patients signed a general consent to use their data for scientific purposes at the beginning of 2016, allowing retrospective data analysis.

\section{Disclosure Statement}

The authors declare no competing interests.

\section{Funding Sources}

This work did not receive any funding.

\section{Author Contributions}

L.B. and M.S. conceived the design of the case series. G.R., L.B., and M.S. treated the patients. L.R. extracted the data and wrote the draft version of the manuscript with critical input from L.B., M.S., and G.R.

\section{References}

1 Shealy DJ, Cai A, Staquet K, Baker A, Lacy ER, Johns L, Vafa O, Gunn G, Tam S, Sague S, Wang D, Brigham-Burke M, Dalmonte $\mathrm{P}$, Emmell E, Pikounis B, Bugelski PJ, Zhou H, Scallon BJ, Giles-Komar J: Characterization of golimumab, a human monoclonal antibody specific for human tumor necrosis factor $\alpha$. MAbs 2010;2:428-439.

2 Kay J, Matteson EL, Dasgupta B, Nash P, Durez P, Hall S, Hsia EC, Han J, Wagner C, Xu Z, Visvanathan S, Rahman MU: Golimumab in patients with active rheumatoid arthritis despite treatment with methotrexate: a randomized, double-blind, placebo-controlled, dose-ranging study. Arthritis Rheum 2008; 58:964-975.

-3 Keystone EC, Genovese MC, Hall S, Miranda PC, Bae S-C, Palmer W, Wu Z, Xu S, Hsia EC: Golimumab in patients with active rheumatoid arthritis despite methotrexate therapy: results through 2 years of the GO-FORWARD study extension. J Rheumatol 2013; 40:1097-1103.

Golimumab in Refractory Crohn's

Disease
4 Emery P, Fleischmann RM, Moreland LW, Hsia EC, Strusberg I, Durez P, Nash P, Amante EJB, Churchill M, Park W, Pons-Estel BA, Doyle MK, Visvanathan S, Xu W, Rahman MU: Golimumab, a human anti-tumor necrosis factor alpha monoclonal antibody, injected subcutaneously every four weeks in methotrexate-naive patients with active rheumatoid arthritis: twenty-four-week results of a phase III, multicenter, randomized, doubleblind, placebo-controlled study of golimumab before methotrexate as first-line therapy for early-onset rheumatoid arthritis. Arthritis Rheum 2009;60:2272-2283.

5 Smolen JS, Kay J, Doyle MK, Landewé R, Matteson EL, Wollenhaupt J, Gaylis N, Murphy FT, Neal JS, Zhou Y, Visvanathan S, Hsia EC, Rahman MU: Golimumab in patients with active rheumatoid arthritis after treatment with tumour necrosis factor alpha inhibitors (GOAFTER study): a multicentre, randomised, double-blind, placebo-controlled, phase III trial. Lancet 2009;374:210-221.
Kremer J, Ritchlin C, Mendelsohn A, Baker D, Kim L, Xu Z, Han J, Taylor P: Golimumab, a new human anti-tumor necrosis factor alpha antibody, administered intravenously in patients with active rheumatoid arthritis: fortyeight-week efficacy and safety results of a phase III randomized, double-blind, placebocontrolled study. Arthritis Rheum 2010;62: 917-928.

7 Braun J, Baraliakos X, Hermann K-GA, van der Heijde D, Inman RD, Deodhar AA, Baratelle A, Xu S, Xu W, Hsu B: Golimumab reduces spinal inflammation in ankylosing spondylitis: MRI results of the randomised, placebo- controlled GO-RAISE study. Ann Rheum Dis 2012;71:878-884. 
8 Kavanaugh A, van der Heijde D, McInnes IB, Mease P, Krueger GG, Gladman DD, GómezReino J, Papp K, Baratelle A, Xu W, Mudivarthy S, Mack M, Rahman MU, Xu Z, Zrubek J, Beutler A: Golimumab in psoriatic arthritis: one-year clinical efficacy, radiographic, and safety results from a phase III, randomized, placebo-controlled trial. Arthritis Rheum 2012;64:2504-2517.

-9 Sandborn WJ, Feagan BG, Marano C, Zhang $\mathrm{H}$, Strauss R, Johanns J, Adedokun OJ, Guzzo C, Colombel J-F, Reinisch W, Gibson PR, Collins J, Jarnerot G, Hibi T, Rutgeerts P: Subcutaneous golimumab induces clinical response and remission in patients with moderate-to-severe ulcerative colitis. Gastroenterology 2014;146:85-95; quiz e14-15.
10 Sandborn WJ, Feagan BG, Marano C, Zhang $\mathrm{H}$, Strauss R, Johanns J, Adedokun OJ, Guzzo C, Colombel J-F, Reinisch W, Gibson PR, Collins J, Jarnerot G, Rutgeerts P: Subcutaneous golimumab maintains clinical response in patients with moderate-to-severe ulcerative colitis. Gastroenterology 2014;146:96-109.e1.

-11 Merras-Salmio L, Kolho K-L: Golimumab therapy in six patients with severe pediatric onset Crohn disease. J Pediatr Gastroenterol Nutr 2016;63:344-347.

12 Danese S, Vuitton L, Peyrin-Biroulet L: Biologic agents for IBD: practical insights. Nat Rev Gastroenterol Hepatol 2015;12:537-545.

13 Neurath MF: New targets for mucosal healing and therapy in inflammatory bowel diseases. Mucosal Immunol 2014;7:6-19.

14 Sandborn WJ: The present and future of inflammatory bowel disease treatment. Gastroenterol Hepatol 2016;12:438-441.
15 Scharl M, Frei P, Fried M, Rogler G, Vavricka SR: Association between Cogan's syndrome and inflammatory bowel disease: a case series. J Crohns Colitis 2011;5:64-68.

16 Vavricka SR, Greuter T, Scharl M, Mantzaris G, Shitrit AB, Filip R, Karmiris K, Thoeringer CK, Boldys H, Wewer AV, Yanai H, Flores C, Schmidt C, Kariv R, Rogler G, Rahier J-F: Cogan's syndrome in patients with inflammatory bowel disease - a case series. J Crohns Colitis 2015;9:886-890

17 Allez M, Vermeire S, Mozziconacci N, Michetti P, Laharie D, Louis E, Bigard M-A, Hébuterne X, Treton X, Kohn A, Marteau P, Cortot A, Nichita C, van Assche G, Rutgeerts P, Lémann M, Colombel J-F: The efficacy and safety of a third anti-TNF monoclonal antibody in Crohn's disease after failure of two other anti-TNF antibodies. Aliment Pharmacol Ther 2010;31:92-101. 